\title{
Association between parental socioeconomic status with underweight and obesity in children from two Spanish birth cohorts: a changing relationship
}

Vicente Martínez-Vizcaíno ${ }^{1,2^{*}}$, Montserrat Solera-Martínez', Iván Cavero-Redondo1, Jorge Cañete García-Prieto1, Natalia Arias-Palencia ${ }^{1}$, Blanca Notario-Pacheco ${ }^{1}$, Maria Martínez-Andrés ${ }^{1}$, Jorge Mota ${ }^{3}$,

Mairena Sánchez-López ${ }^{1,4}$ and on behalf of Cuenca Study Group

\begin{abstract}
Background: Our objective was twofold: to estimate the prevalence of underweight, overweight, and obesity in two birth cohorts (1999-2000 and 2007-2008) from Castilla-La Mancha, Spain; and to examine the association between parental socioeconomic status (SES) and weight status in these two cohorts.

Methods: Cross-sectional analysis of baseline measurements was utilised in two cluster randomised trials. Using population-based samples of children from Castilla-La Mancha, Spain, 1158 children with a mean age of 9.5 years, born in the years 1999-2000 and 1588 children with a mean age of 5.3 years born in the years 2007-2008 participated. Children were classified according to the body mass index cut-offs proposed by the International Obesity Task Force criteria. An index of SES was calculated using questions regarding parental education and occupation levels.
\end{abstract}

Results: Prevalence of underweight was higher in the 2007-2008 birth cohort $(20.5 \%, 95 \% \mathrm{Cl}$ : 18.5, 22.5) than in the 1999-2000 birth cohort (8.1 \%, $95 \%$ Cl: 6.5, 9.7), and the overweight/obesity prevalence was $20.4 \%$ (95\% Cl: $18.4,22.5)$ and $35.5 \%(95 \%$ Cl: $32.7,38.3)$ respectively. In the lower SES stratum, in the 2007-2008 birth cohort, the prevalence of underweight and overweight/obesity was $36.7 \%$ (95 \% Cl: 22.2, 51.2) and $16.3 \%$ (95 \% Cl: 4.9, 27.7) respectively, and $22.2 \%(95 \% \mathrm{Cl}: 2.8,60.0)$ and $55.5 \%(95 \% \mathrm{Cl}: 21.2,86.3)$ in the $1999-2000$ cohort. The ratio between underweight:overweight/obesity showed higher values for all SES categories in 2007-2008 cohort, but particularly in the lower SES group (0.4 in the 1999-2000 cohort and 2.2 in the 2007-2008 cohort).

Conclusion: Underweight prevalence was lower in the cohort of children born in 1999-2000, and the prevalence of overweight and obesity was lower in the cohort of children born in 2007-2008. Furthermore, while in the 1999-2000 children's cohort underweight was more frequent amongst children from high SES families and overweight/obesity was more frequent in children from low SES families, in the 2008-2009 children's cohort the opposite was true.

Keywords: Child health, Weight status, Socioeconomic status

\footnotetext{
* Correspondence: Vicente.Martinez@uclm.es

'Universidad de Castilla-La Mancha: Health and Social Research Center,

Cuenca, Castilla-La Mancha, España

${ }^{2}$ Facultad de Ciencias de la Salud, Universidad Autónoma de Chile, Talca,

Chile

Full list of author information is available at the end of the article
} 


\section{Background}

Prevalence of obesity and overweight have risen substantially in the past three decades in Spain [1] and most countries, even though marked variations in the estimations across countries have been reported [2]. The excess weight prevalence has grown steadily over the past two decades in Spanish children and also in children from most countries [3] even at early ages [4]. Paradoxically although excess weight in children is increasing worldwide, underweight remains a serious health problem in low income countries [5]. In Spanish children, the increasing trend in the prevalence of obesity has been accompanied by a similar trend in underweight prevalence [1].

The influence of several factors, including genetic, environmental, cultural, and socioeconomic status (SES) on weight status in children has been extensively described [6]. Childhood obesity and overweight have stabilised in England during the last decade, but children from lower SES have not benefited from this trend [7]. While in low income countries obesity in children has been associated with high parental SES and underweight with lower SES, in wealthy countries the opposite is true [8]. In Denmark an increased prevalence of overweight in children from low educational levels families has been attributed to social inequalities, thus it has been proposed that public health initiatives aimed at preventing and reducing excess weight should consider parents' SES level [9].

Children's obesity and parental socioeconomic position have been consistently related. Energy-dense diets are associated with lower daily food consumption costs and may be an effective way to save money. In addition low SES has been associated with less participation in sports or physical activities. However, it is unclear whether parental socioeconomic circumstances affect children's weight status at a young age [10].

From 2008 until today the financial crisis has caused deterioration in the health of Europeans [11] and might have deteriorated the health and welfare of families from some European countries such as Greece, Spain, or Portugal. The economic downturn can be expected to reduce nutrition quality and physical activity, worsening obesity prevalence when society is least able to bear the escalating financial burden [12]. In some regions of Spain between 2005 and 2010, the proportion of children at risk of poverty increased from $20.6 \%$ to $23.7 \%$, and living in unemployed families from $3.7 \%$ to $11.2 \%$ [11].

Our objective was twofold: first, to estimate the prevalence of underweight, overweight, and obesity in both the 1999-2000 and the 2007-2008 birth cohorts from Castilla-La Mancha, Spain; and second, to examine the association between parental socioeconomic levels and weight status in both cohorts of children.

\section{Methods \\ Study design and population \\ Design}

Cross-sectional analysis of the baseline measurements data from two cluster randomised trials aimed to evaluate the effectiveness of leisure-time physical activity on the prevention of childhood obesity: MOVI-2 study and Movi-KIDS study. Both studies included populationbased samples of children from the Castilla-La Mancha region, Spain. Castilla-La Mancha is a central region of Spain, and has more than two million inhabitants (11.00\% immigrants from Eastern Europe, North-Africa, Asian, and South and Central-America) predominantly of low-medium socioeconomic level. The unemployment rate in the Castilla-La Mancha region has increased from approximately $12 \%$ in 2008 to $30 \%$ in 2013.

Participants belonged to two population-based birth cohorts:

a) Year 1999-2000 cohort. Children born in the years 1999-2000 were recruited from the baseline measurements (September-November 2010) of a cluster randomised trial aimed to evaluate the effectiveness of a leisure-time programme of physical activity for the prevention of childhood obesity (clinicaltrials.gov number: NCT01277224). All the fourth and fifth grade primary school children $(n=1,592)$ belonging to 20 public schools from 20 towns in the Castilla-La Mancha province of Cuenca, Spain, were invited to participate, and 1,158 (72.7\% participation rate) accepted; of them, 544 completed questionnaires on parental SES [13].

b) Year 2007-2008 cohort. Children born in the years 2007-2008 participating in the baseline measurements (September-November 2013) of an ongoing cross-over cluster randomised trial (clinicaltrials.gov number: NCT01971840) aimed also at promoting physical activity, but in children aged 4 to 7 years. Children of both third grade of pre-primary education and first grade of primary education $(n=2,407)$ belonging to 21 public schools from the Castilla-La Mancha provinces of Cuenca and Ciudad Real were invited to participate. Out of these 1,588 (66.0\% participation rate) accepted, and 1,398 completed questionnaires on parental SES [14].

\section{Ethical and legal aspects}

The Clinical Research Ethics Committee of the Virgen de la Luz Hospital in Cuenca approved both cluster randomised trials. They were also approved by the Director and Board of Governors (Consejo Escolar) of each school. For data collection, parents gave written consent 
for their child to participate in the study, and children gave verbal consent when they were asked to collaborate in informative talks held class-by-class. After the data were gathered, the parents were informed by letter of their children's results.

\section{Study variables \\ Anthropometry}

In both the 1999-2000 and the 2007-2008 studies, anthropometric measurements were obtained at the schools by trained and certified nurses. Weight was calculated as the mean of two readings on a digital scale (100 g accuracy) with children lightly dressed and without shoes (Seca ${ }^{\oplus}$ 861, Vogel \& Halke, Hamburg, Germany). Height was assessed as the mean of two measures with a wall-mounted height rod (Seca ${ }^{\circledR} 222$, Vogel \& Halke, Hamburg, Germany) on shoeless children standing straight against the wall, so that their spine was vertically aligned with the centre of the height rod. The head was placed with the chin parallel to the floor, and height was measured to the nearest mm. Body mass index (BMI) was calculated as weight in $\mathrm{kg}$ divided by the square of the height in metres. Body fat percentage (BF\%) was estimated with electronic bio-impedance monitoring with the Tanita ${ }^{\circ}$ BC-418 MA model of 8-contact electrode system (Tanita Corp. Tokyo, Japan) in MOVI-2 study and with the Tanita ${ }^{\oplus}$ Segmental-418 model of 4-contact electrode system (Tanita Corp. Tokyo, Japan) in Movi-KIDS study [15]. The body fat percentage was calculated as the mean of two readings obtained in the morning, under controlled temperature and humidity conditions, with the child being shoeless, fasting, after urination and a 15-minute rest, in the two cluster randomised trials.

\section{Parental socioeconomic status}

Data for parental SES were gathered by using selfreported occupation and education questions completed by either the father or the mother. Paternal and maternal education were classified separately as primary education (functionally illiterate, without any studies or had not completed primary education), middle education (primary education or high school/ secondary education) and university education (university degree or PhD). Parental occupation was classified into five categories: 1 . supervisor/manager or freelance with 10 employees or more, 2. supervisor/manager or freelance with less than 10 employees, 3. freelance with no staff, 4. non-qualified staff and unskilled worker, and 5. household chores, unemployed and others. An index of SES was calculated with the items that referred to the parents' education and parental occupation classifying SES as: lower, lower middle, middle, upper middle, and upper according to the scale proposed by the Spanish Society of Epidemiology [16].

\section{Statistical analysis}

Children were classified as underweight, normal weight, overweight, and obese according to the BMI cut-offs proposed by the International Obesity Task Force (IOTF) [17]. Differences in the frequency of each weight status category between boys and girls were assessed with the chi-squared test. Differences in body composition variables were tested by unpaired t-tests.

Differences in the mean of body composition variables by parental SES categories (five and three categories) were assessed using analysis of covariance (ANCOVA) controlling for age.

Logistic regression models were used to examine the association between three SES levels (middle SES was used as a reference category) and weight status categories. Odds ratios (ORs) and the $95 \%$ confidence intervals (CIs) were estimated.

Analyses were performed with IBM SPSS Statistics 22 (SPSS, Inc., Chicago, IL), and statistical significance was set at two tailed $\mathrm{p} \leq 0.05$.

\section{Results}

The mean age range at the examination in the 19992000 cohort was 8-11 years and 4-7 years in the 20072008 cohort. Using IOTF cut-off points, the prevalence of underweight was higher in the 2007-2008 birth cohort $(20.5 \%, 95 \%$ CI: 18.5, 22.5) than in the 1999-2000 birth cohort $(8.1 \%, 95 \%$ CI: 6.5, 9.7). Moreover excess weight prevalence (overweight/obesity) estimates were $35.5 \%$ (95 \% CI: 32.7, 38.3) for the 1999-2000 cohort and $20.4 \%$ (95 \% CI: 18.4, 22.5) for the 2007-2008 cohort. In both cohorts were similar the age, sex and anthropometric characteristics of those children whose parents responded to the SES questionnaire and those who did not do so (Table 1).

There were statistically significant gender differences in the mean of BF\% (higher in girls, $p<0.001$ ) and for BMI for age z-scores (higher in boys, $p<0.01$ ) in the 1999-2000 cohort (Table 2).

In the lower SES stratum, in the 2007-2008 birth cohort, the prevalence of underweight was $36.7 \%$ (95\% CI: 22.2, 51.2), and $22.2 \%(95 \%$ CI: 2.8, 60.0) in the 1999-2000 cohort (Table 3). No remarkable differences were found in excess weight prevalence by parental SES between both cohorts. The ratio underweight: overweight/obesity showed higher values for all SES categories in 2007-2008 cohort, but particularly in the lower SES group (0.4 in the 1999-2000 cohort and 2.2 in the 2007-2008 cohort). Additional file 1 displays the frequency of weight status categories by parental SES with three categories in the 1999-2000 and 2007-2008 birth cohorts.

Similar results were observed when we separately analysed the children of immigrant parents and of Spanish 
Table 1 Body composition variables, weight status and parental socio-economic status in the study cohorts, by familial response behavior

\begin{tabular}{|c|c|c|c|c|c|c|}
\hline & \multicolumn{6}{|l|}{ Birth cohort } \\
\hline & \multicolumn{3}{|c|}{$1999-2000(n=1158)$} & \multicolumn{3}{|c|}{$2007-2008(n=1588)$} \\
\hline & Respondents SES & Non-respondents SES & Total & Respondents SES & Non-respondents SES & Total \\
\hline Boys, n (\%) & $253(46.5)$ & $334(54.2)$ & $587(50.7)$ & $715(51.1)$ & $91(47.9)$ & $806(50.8)$ \\
\hline Girls, n (\%) & $291(53.5)$ & $280(45.5)$ & $571(49.3)$ & $571(48.9)$ & $99(52.1)$ & $782(49.2)$ \\
\hline Age mean, years (range) & $9.4(8-11)$ & $9.7(8-11)$ & $9.5(8-11)$ & $5.3(4-7)$ & $5.4(4-7)$ & $5.3(4-7)$ \\
\hline \multicolumn{7}{|c|}{ Body composition variables, mean (SD) } \\
\hline Weight (kg) & $37.3(9.3)$ & $37.4(9.1)$ & $37.3(9.2)$ & $21.3(4.7)$ & $21.7(5.0)$ & $21.4(4.8)$ \\
\hline Height (cm) & $139.6(7.2)$ & $139.5(6.8)$ & $139.6(7.0)$ & $115.4(6.1)$ & $115.7(5.8)$ & $115.5(6.1)$ \\
\hline BMI $\left(\mathrm{kg} / \mathrm{m}^{2}\right)$ & $19.0(3.7)$ & $19.0(3.7)$ & $19.0(3.7)$ & $15.9(2.4)$ & $16.0(2.6)$ & $15.9(2.5)$ \\
\hline $\mathrm{BF} \%$ & $25.4(6.6)$ & $25.2(6.9)$ & $25.3(6.8)$ & $20.1(5.8)$ & $20.5(6.2)$ & $20.2(5.8)$ \\
\hline \multicolumn{7}{|c|}{ Weight status categories, \% (95 \% Cl) } \\
\hline Underweight & $7.5(5.2-9.8)$ & $8.6(6.3-10.9)$ & $8.1(6.5-9.7)$ & $20.5(18.4-22.7)$ & $20.5(14.5-26.5)$ & $20.5(18.5-22.5)$ \\
\hline Normal weight & $57.4(53.1-61.6)$ & $55.4(51.5-59.5)$ & $56.4(53.5-59.3)$ & $59.2(56.5-61.8)$ & $57.9(50.6-65.2)$ & $59.0(56.5-61.4)$ \\
\hline Overweight & $25.9(22.1-29.7)$ & $25.0(21.6-28.6)$ & $25.5(22.9-28.0)$ & $12.0(10.3-13.7)$ & $10.5(5.9-15.1)$ & $11.8(10.2-13.4)$ \\
\hline Obesity & $9.2(6.7-11.7)$ & $10.7(8.2-13.3)$ & $10.0(8.2-11.8)$ & $8.3(6.8-9.8)$ & $11.1(6.3-15.8)$ & $8.6(7.2-10.0)$ \\
\hline Overweight/obesity & $35.1(31.0-39.2)$ & $35.7(31.9-39.7)$ & $35.5(32.7-38.3)$ & $20.3(18.2-22.5)$ & $21.6(15.5-27.7)$ & $20.4(18.4-22.5)$ \\
\hline \multicolumn{7}{|c|}{ Parental socio-economic status, \% (95% Cl) } \\
\hline & $N=544$ & & & $N=1398$ & & \\
\hline Lower & $1.6(0.5-2.9)$ & & & $3.5(2.5-4.5)$ & & \\
\hline Lower middle & $18.9(15.5-22.3)$ & & & $27.3(24.9-29.7)$ & & \\
\hline Middle & $38.2(34.1-42.4)$ & & & $44.8(42.2-47.5)$ & & \\
\hline Upper middle & $31.8(27.8-35.8)$ & & & $19.9(17.8-22.1)$ & & \\
\hline Upper & $9.4(6.8-11.9)$ & & & $4.4(3.2-5.5)$ & & \\
\hline
\end{tabular}

Abbreviations: $B M I$ body mass index, $B F \%$ body fat percentage, $S D$ Standard deviation, $C I$ confidence interval

Table 2 Gender differences in body composition and weight status categories, by birth cohort

\begin{tabular}{|c|c|c|c|c|c|c|}
\hline & \multicolumn{6}{|l|}{ Birth cohort } \\
\hline & \multicolumn{3}{|c|}{$1999-2000(n=1158)$} & \multicolumn{3}{|c|}{$2007-2008(n=1588)$} \\
\hline & Boys & Girls & & Boys & Girls & \\
\hline & $n=587$ & $n=571$ & $\mathrm{p}$ & $n=806$ & $n=782$ & $\mathrm{p}$ \\
\hline \multicolumn{7}{|c|}{ Body composition variables, mean (SD) } \\
\hline $\mathrm{BMI}\left(\mathrm{kg} / \mathrm{m}^{2}\right)$ & $19.2(3.8)$ & $18.8(3.5)$ & 0.1 & $16.0(2.5)$ & $15.8(2.5)$ & 0.2 \\
\hline $\mathrm{BF} \%$ & $23.9(7.1)$ & $26.8(6.1)$ & $<0.001$ & $20.0(5.2)$ & $20.4(6.4)$ & 0.2 \\
\hline BMl-for-age z-score & $0.9(1.4)$ & $0.7(1.3)$ & 0.002 & $0.2(1.4)$ & $0.1(1.4)$ & 0.1 \\
\hline \multicolumn{7}{|c|}{ Weight status categories, \% (95 \% Cl) } \\
\hline Underweight & $8.5(6.2-10.9)$ & $7.7(5.4-10.0)$ & 0.69 & $19.9(17.0-22.7)$ & $21.2(18.3-24.1)$ & 0.54 \\
\hline Normal weight & $53.8(49.7-57.9)$ & $59.0(54.9-63.1)$ & 0.08 & $61.4(58.0-64.8)$ & $56.5(52.9-60.1)$ & 0.05 \\
\hline Overweight & $27.1(23.4-30.8)$ & $23.8(20.2-27.4)$ & 0.23 & $10.3(8.1-12.4)$ & $13.4(11.0-15.9)$ & 0.06 \\
\hline Obesity & $10.6(7.9-13.1)$ & $9.5(7.0-11.9)$ & 0.60 & $8.4(6.4-10.4)$ & $8.8(6.8-10.9)$ & 0.85 \\
\hline Overweight/ obesity & $37.7(33.6-41.6)$ & $33.3(29.3-37.2)$ & 0.13 & $18.7(16.0-21.3)$ & $22.2(19.3-25.2)$ & 0.09 \\
\hline
\end{tabular}


Table 3 Differences in frequencies of children in weight status categories by parental socio-economic status, controlling for age in the study birth cohorts

\begin{tabular}{|c|c|c|c|c|c|c|c|c|c|c|}
\hline \multicolumn{6}{|c|}{ Birth cohort 1999-2000 $(n=544)$} & \multicolumn{5}{|c|}{ Birth cohort 2007-2008 $(n=1398)$} \\
\hline \multicolumn{11}{|c|}{ Parental socio-economic status } \\
\hline & Lower & Lower middle & Middle & Upper middle & Upper & Lower & Lower middle & Middle & Upper middle & Upper \\
\hline & $n=9$ & $n=103$ & $n=208$ & $n=173$ & $n=51$ & $n=49$ & $n=382$ & $n=627$ & $n=279$ & $n=61$ \\
\hline Underweight & $22.2(2.8-60.0)$ & $5.8(0.8-10.8)$ & $7.7(3.8-11.5)$ & $6.9(2.9-11.0)$ & $9.8(3.3-21.4)$ & $36.7(22.2-51.2)$ & $19.6(15.5-23.7)$ & $21.0(17.8-24.3)$ & $19.7(14.9-24.6)$ & $11.5(2.6-20.3)$ \\
\hline Normal weight & $22.2(2.8-60.0)$ & $54.4(44.3-64.5)$ & $59.1(52.2-66.0)$ & $59.0(51.3-66.6)$ & $56.8(42.2-71.4)$ & $46.9(31.9-61.9)$ & $58.1(53.0-63.2)$ & $59.0(55.1-62.9)$ & $62.4(56.5-68.2)$ & $62.3(49.3-75.3)$ \\
\hline Overweight & $33.3(7.5-70.1)$ & $25.2(16.4-34.1)$ & $25.5(19.3-31.6)$ & $28.3(21.3-35.3)$ & $19.6(7.7-31.5)$ & $6.1(1.3-16.9)$ & $13.1(9.6-16.6)$ & $11.3(8.8-13.9)$ & $11.8(7.8-15.8)$ & $18.0(7.6-28.5)$ \\
\hline Obesity & $22.2(2.8-60.0)$ & $14.6(7.3-21.9)$ & $7.7(3.8-11.5)$ & $5.8(2.0-9.5)$ & $13.7(3.3-24.1)$ & $10.2(3.4-22.2)$ & $9.2(6.1-12.2)$ & $8.6(6.3-10.9)$ & $6.1(3.1-9.1)$ & $8.2(2.7-18.1)$ \\
\hline Overweight/ obesity & $55.5(21.2-86.3)$ & $39.8(29.9-49.7)$ & $33.2(26.5-39.8)$ & $34.1(26.7-41.4)$ & $33.3(19.4-47.2)$ & $16.3(4.9-27.7)$ & $22.2(17.9-26.5)$ & $19.9(16.7-23.1)$ & $17.9(13.2-22.6)$ & $26.2(14.4-38.1)$ \\
\hline Ratio UW:OV/OB & 0.4 & 0.1 & 0.2 & 0.2 & 0.3 & 2.2 & 0.9 & 1.0 & 1.1 & 0.4 \\
\hline
\end{tabular}

Abbreviations: UW : OV/OB, Ratio underweight overweight/obesity 
parents separately, when we separately analysed the data from the children from the province of Cuenca and those from Ciudad Real separately in the 2007-2008 birth cohort (Additional file 2), and when the analyses, in both cohorts, were stratified by sex (Additional file 3).

The ORs for the association between three SES categories and weight status using logistic regression models, considering middle SES level as a reference category, were similar in both cohorts (Additional file 4).

\section{Discussion}

The present study revealed that in both genders, in the cohort of children born in 1999-2000 the prevalence of underweight was lower and the prevalence of overweight/obesity was higher than in the cohort of 2007-2008. In addition, this study showed that the relationship between parental SES and children's body composition has been substantially modified. While in the 1999-2000 cohort underweight was more frequent amongst children from high SES families and overweight/obesity was more frequent in children from low SES families, in the 2007-2008 children's cohort the opposite was true.

The strengths of this study included that we have clearly described the procedures we followed to estimate and analyse our data. To our knowledge this is the only study that has examined the prevalence of underweight and overweight/obesity in Spanish children born before and after the 2008 financial crisis, and also examined the association between SES and weight status in these cohorts. We consider the data of this study very important from the point of view of public health as they suggest that Spanish children, the most vulnerable population group, are already suffering the consequences of the economic crisis; but also amongst other child populations where the social inequalities are growing which could be influencing their weight status distribution.

Our study had some limitations. First, the nature of the cross-sectional analysis of the baseline measurements data from two cluster randomised trials should be considered when interpreting the findings. Second, the age of the two cohorts was different at the measurement date, thus it is not possible to assume that changes in the prevalence of both overweight and obesity were not similar changes to those that have occurred in successive cohorts before and after the financial crisis; however, it is difficult to assume that stature percentiles at earlier ages do not continue to puberty and adolescence. Third, the distribution of SES changes over time, thus it is possible that changes in SES population distribution influence the statistical power in comparisons, therefore the absolute magnitude of differences should be taken into account. Fourth, the cohort effect prevents us from assuming that the same findings are valid for other cohorts before and after the financial crisis. Fifth, parental response rate for the SES questionnaire was considerably lower in the 1999-2000 cohort and this may have a bearing on the analysis of the results. Sixth, differences in children whose parents did respond to SES questions and those who did not could threaten the validity of the study, but Table 1 data indicated that the two subgroups were similar.

Childhood obesity continues to increase in some countries while in other countries it has apparently plateaued. A study in the US including data from 1999 to 2010 described an increasing trend in the prevalence of obesity amongst children and adolescents [18]. In Australia, studies published from 1996 to 2008 did not find substantial changes in childhood obesity prevalence [19]. A study in Switzerland reported that there was a decrease in obesity prevalence among children 6 through 13 years of age between 2002 and 2007 [20]. Our data providing information from two cohorts at different ages suggests that the children's obesity epidemic could be starting to reverse, but new studies comparing children at the same age from different birth cohorts should be conducted in order to definitely clarify this concern, since the 2007-2008 figures might simply represent a cohort effect, and subsequent cohorts could return to previous figures.

International Obesity Task Force criteria (IOTF) were used in this analysis because their cut-offs for children are representative of the population of the whole world [17]. Predictions about the future prevalence of overweight in children from the industrialised countries are not consistent, since while some studies have warned about the need for effective interventions to reverse anticipated alarming trends [4, 21], other studies have emphasised the scarcity of data for early ages [22], and have even recently reported an unexpected stabilisation or decline in the prevalence of overweight in developed countries [23-25]. Our data showed that the prevalence of overweight/obesity in children from Castilla-La Mancha, Spain was lower in the 2007-2008 birth cohort than in 1999-2000, breaking down the upward trend that from 1992 to 2010 had been reported in the same population [1]. Several possible reasons have been argued to explain the stabilisation in childhood overweight/obesity rates, among them the cumulative effect of intervention programmes aimed at promoting healthy eating and physical activity, and also that the obesity epidemic has reached an equilibrium point between obesogenic environment and some degree of socially programmed resilience [23]. However, at least in the Mediterranean countries, we cannot rule out the influence of the financial crisis on the shocking increase of social inequality between 2007 and 2011 [26], such that 
$29.9 \%$ of Spanish children and adolescents are estimated to live below the poverty line [27].

Since 1989 to 2005 the association between SES and adiposity in children from western developed countries was predominately inverse [28], thus it was widely accepted that the low-SES families from these countries were at greater risk of excess weight than the higher-SES families [29]. However, from the financial crisis, this view has been challenged. Our data showed that in the 1999-2000 children's cohort adiposity was negatively associated with parental SES level, and in the 2007-2008 cohort the opposite was true. Several arguments might be outlined to explain this change in the relationship between parental SES and children adiposity, and among them the more reasonable might be related to the fact that subsidies for meals provided to children from low SES families in the schools have been removed during the last years [30], and it is conceivable that the most economically vulnerable families do not have sufficient resources to ensure minimum food for their children.

However, so far, the economic crisis impact on the health of the Spanish population is a debatable issue. A recent analysis reported the null impact of the economic crisis not only in premature mortality but also in selfreported health status [31]. However, another study predicted that, as the percentage of children below the poverty line has grown steadily from the onset of the financial crisis, the health consequences will soon appear [32] and, evidence suggests, might endure throughout a lifespan [33]. Our data showed that, as expected, the economic crisis impact has appeared in children of an early age, the most vulnerable population.

\section{Conclusions}

Our data revealed that in both genders, underweight prevalence was lower in the cohort of children born in the wealthy years, and the prevalence of overweight and obesity was lower in the cohort of children born during the financial crisis. Also, our results showed that while in the 1999-2000 children's cohort underweight was more frequent amongst children from high SES families and overweight/obesity was more frequent in children from low SES families, in the 2007-2008 children's cohort the opposite was true. Therefore, our data should serve to alert Spanish and other countries' welfare authorities about this issue, and might be useful to prioritise policies in order to minimise the impact of poverty on children's development. Moreover, since no studies have compared the prevalence of underweight and excess weight in cohorts of children born before and during the 2008 economic recession, our data also highlight the convenience of monitoring growth indicators in children from cohorts born after the financial crisis.

\section{Additional files}

Additional file 1: Differences in weight status by parental socioeconomic status, controlling for age in the study, by birth cohort. (DOC $34 \mathrm{~kb}$ )

Additional file 2: Differences in frequencies of children in weight status categories by parental socio-economic status in birth cohort 2007-2008, controlling for age by parents nationalities and provinces. (DOC $46 \mathrm{~kb}$ )

Additional file 3: Differences in weight status by parental socioeconomic status, controlling for age, by sex. (DOC $46 \mathrm{~kb}$ )

Additional file 4: Socioeconomic status ${ }^{1}$ as predictor of underweight and overweight/obesity in logistic regression models controlling for age, by sex. (DOC $35 \mathrm{~kb}$ )

\section{Abbreviations}

SES: socioeconomic status; BMI: body mass index; IOTF: International Obesity Task Force; ANCOVA: analysis of covariance; OR: Odds ratio.

\section{Competing interests}

The authors declare no conflicts of interests. All authors declare that the following statements are true: they received no support from any organisation for the submitted work; they conducted no financial relationships with any organisations that might have an interest in the submitted work in the previous years; there were no other relationships or activities that could appear to have influenced the submitted work.

\section{Authors' contributions}

VMV and MSL designed the study. VMV was the principal investigator and guarantor. All authors established the methods and questionnaires. MSL, $B N P$, and VMV were the main coordinators of the study. MSL, NAP, JCGP, and BNP conducted the study. MSM and ICR gave statistical and epidemiological support. VMV wrote the article with the support of MSL, MSM, ICR, JM and MMA. VMV obtained the funding, with the assistance of MSL. All authors provided comments on the drafts and have read and approved the final version.

\section{Acknowledgements}

This study was funded by the Ministry of Economy and CompetitivenessCarlos III Health Institute and FEDER funds (FIS PI12/02400 and FIS PI12/ 00761), the Ministry of Education and Science-Junta de Comunidades de Castilla-La Mancha (PII1109- 0259-9898 and POII10-0208-5325) and the Ministry of Health (FIS P1081297). Additional funding was obtained from the Research Network on Preventative Activities and Health Promotion (Refs. - RD06/0018/0038 and RD12/0005/0009).

The authors would like to thank all children, their parents, the school teachers, and the respective school health services for their participation and help in the study. We thank all members of the Cuenca Study* who helped make this study possible.

*In addition to the authors in the Cuenca Study Group, the following are included: Fernando Salcedo Aguilar, Celia Álvarez Bueno, Diana P. Pozuelo Carrascosa, María Jesús Pardo-Guijarro, Lydia Lucas de la Cruz, Coral Estefanía Torrijos Niño, Alberto González García, Pablo Franquelo Morales, José Luis Santos Gómez, Marta Guijarro Herraiz, Sergio Jiménez Suarez, Julián Gil Martínez, Javier Álvarez Álvarez, Carlos Javier Piera Cejalvo, Patricia Picazo Serrano, Ricardo Martínez Olivas, Pablo Diego Madrid, Jennifer Rosa Martínez Rey, Inmaculada Navalón Cañas, Sara Albadalejo Arribas, Pedro Miguel Ribeiro da Silva, Francisco J. García Sánchez, Inmaculada Díaz Jiménez, David Gutiérrez Díaz del Campo, Roberto Gulias Gómez, Ana Díez Fernández, Ma José González López, Verónica Artalejo de Mora, Alberto Bermejo Cantarero, Irene Rivero Merino, Julia Muñoz Pinilla, Marta Terán Boabén, Santiago Amador Ruiz, Antonio Sánchez Gavidia, Alberto José Cerrillo Urbina, Paloma Moreno Escobar, Minerva Velasco Abellán, Noelia María Martín Espinosa, Ma Ángeles Suarez Gómez, Abel Ruiz de la Hermosa Fernández-Infante.

\section{Author details}

${ }^{1}$ Universidad de Castilla-La Mancha: Health and Social Research Center, Cuenca, Castilla-La Mancha, España. ²Facultad de Ciencias de la Salud, 
Universidad Autónoma de Chile, Talca, Chile. ${ }^{3}$ Research Centre in Physical Activity, Health and Leisure, University of Porto, Porto, Portugal. ${ }^{4}$ Universidad de Castilla-La Mancha: School of Education, Ciudad Real, Castilla-La Mancha, España.

Received: 14 July 2015 Accepted: 3 December 2015

Published online: 22 December 2015

\section{References}

1. Martínez-Vizcaíno V, Solera-Martinez M, Notario-Pacheco B, Sánchez-López M, García-Prieto JC, Torrijos-Niño C, et al. Trends in excess of weight, underweight and adiposity among Spanish children from 2004 to 2010: the Cuenca Study. Public Health Nutr. 2012;15:2170-4.

2. Ng M, Fleming T, Robinson M, Thompson B, Graetz N, Margono C, et al. Global, regional, and national prevalence of overweight and obesity in children and adults during 1980-2013: a systematic analysis for the Global Burden of Disease Study 2013. Lancet. 2014;384:766-81.

3. Wang Y, Lobstein T. Worldwide trends in childhood overweight and obesity. Int J Pediatr Obes. 2006;1:11-25.

4. De Onis M, Blössner M, Borghi E. Global prevalence and trends of overweight and obesity among preschool children. Am J Clin Nutr. 2010;92:1257-64.

5. Black RE, Victora CG, Walker SP, Bhutta ZA, Christian P, De Onis M, et al. Maternal and child undernutrition and overweight in low-income and middle-income countries. Lancet. 2013;382:427-51.

6. Sanchez-Cruz J, de Ruiter I, Jimenez-Moleon J. Individual, family and environmental factors associated with pediatric excess weight in Spain: a cross-sectional study. BMC Pediatr. 2014:14:3.

7. Stamatakis E, Wardle J, Cole TJ. Childhood obesity and overweight prevalence trends in England: evidence for growing socioeconomic disparities. Int J Obesity. 2009;34:41-7.

8. Shrewsbury V, Wardle J. Socioeconomic status and adiposity in childhood: a systematic review of cross-sectional studies 1990-2005. Obesity. 2008;16:275-84.

9. Matthiessen J, Stockmarr A, Biltoft-Jensen A, Fagt S, Zhang H, Groth MV. Trends in overweight and obesity in Danish children and adolescents: 20002008-exploring changes according to parental education. Scand J Public Healt. 2014;42:385-92.

10. Stamatakis E, Primatesta P, Chinn S, Rona R, Falascheti E. Overweight and obesity trends from 1974 to 2003 in English children: what is the role of socioeconomic factors? Arch Dis Child. 2005;90(10):999-1004.

11. Karanikolos M, Mladovsky P, Cylus J, Thomson S, Basu S, Stuckler D, et al. Financial crisis, austerity, and health in Europe. Lancet. 2013;381:1323-31.

12. Ludwig DS, Pollack HA. Obesity and the economy: from crisis to opportunity. JAMA. 2009;301(5):533-5.

13. Martínez-Vizcaíno V, Sánchez-López M, Salcedo-Aguilar F, Notario-Pacheco B, Solera-Martinez M, Moya-Martinez $\mathrm{P}$, et al. Protocol of a randomized cluster trial to assess the effectiveness of the MOVI-2 program on overweight prevention in schoolchildren. Rev Esp Cardiol. 2012;65:427-33.

14. Martínez-Vizcaino V, Mota J, Solera-Martínez M, Notario-Pacheco B, AriasPalencia N, García-Prieto JC, et al. Rationale and methods of a randomised cross-over cluster trial to assess the effectiveness of MOVI-KIDS on preventing obesity in pre-schoolers. BMC Public Health. 2015;15(1):176.

15. Barreira TV, Staiano AE, Katzmarzyk PT. Validity assessment of a portable bioimpedance scale to estimate body fat percentage in white and AfricanAmerican children and adolescents. Pediatr Obes. 2013;8:29-32

16. Domingo-Salvany A, Regidor E, Alonso J, Alvarez-Dardet C. Proposal for a social class measure. Working Group of the Spanish Society of Epidemiology and the Spanish Society of Family and Community Medicine. Atencion Primaria/Sociedad Espanola De Medicina De Familia y Comunitaria. 2000;25(5):350.

17. Cole TJ, Lobstein T. Extended international (IOTF) body mass index cut-offs for thinness, overweight and obesity. Pediatr Obes. 2012;7:284-94.

18. Ogden CL, Carroll MD, Kit BK, Flegal KM. Prevalence of obesity and trends in body mass index among US children and adolescents, 1999-2010. JAMA. 2012;307(5):483-90.

19. Olds TS, Tomkinson GR, Ferrar KE, Maher CA. Trends in the prevalence of childhood overweight and obesity in Australia between 1985 and 2008. Int J Obesity. 2010;34(1):57-66.
20. Aeberli I, Ammann RS, Knabenhans M, Molinari L, Zimmermann MB. Decrease in the prevalence of paediatric adiposity in Switzerland from 2002 to 2007. Public Health Nutr. 2010;13(06):806-11.

21. Kelly T, Yang W, Chen CS, Reynolds K, He J. Global burden of obesity in 2005 and projections to 2030. Int J Obesity. 2008;32:1431-7.

22. Cattaneo A, Monasta L, Stamatakis E, Lioret S, Castetbon K, Frenken F, et al. Overweight and obesity in infants and pre-school children in the European Union: a review of existing data. Obes Rev. 2010;11:389-98.

23. Olds T, Maher C, Zumin S, Peneau S, Lioret S, Castetbon K, et al. Evidence that the prevalence of childhood overweight is plateauing: data from nine countries. Int J Pediatr Obes. 2011;6:342-60

24. Rokholm B, Baker JL, Sørensen TI. The levelling off of the obesity epidemic since the year 1999 - a review of evidence and perspectives. Obes Rev. 2010;11:835-46.

25. Wabitsch M, Moss A, Kromeyer-Hauschild K. Unexpected plateauing of childhood obesity rates in developed countries. BMC Med. 2014;12:17.

26. OCDE. http://www.oecd.org/social/inequality-and-poverty.htm (2014). Accessed 15 June 2014

27. Eurofound. Third European Quality of Life Survey - Quality of life in Europe: Impacts of the crisis. Luxembourg: Publications Office of the European Union; 2012.

28. Shrewsbury V, Wardle J. Socioeconomic Status and Adiposity in Childhood: A Systematic Review of Cross-sectional Studies 1990-2005. Obesity. 2008;16(2):275-84.

29. Wang Y, Zhang Q. Are American children and adolescents of low socioeconomic status at increased risk of obesity? Changes in the association between overweight and family income between 1971 and 2002. Am J Clin Nutr. 2006;84(4):707-16.

30. De Pee S, Brinkman HJ, Webb P, Godfrey S, Darnton-Hill I, Alderman H, et al. How to ensure nutrition security in the global economic crisis to protect and enhance development of young children and our common future. J Nutr. 2010;140(1):138-42.

31. Regidor E, Barrio G, Bravo MJ, de la Fuente L. Has health in Spain been declining since the economic crisis? J Epidemiol Commun H. 2014;68:280-2.

32. Flores M, Garcia-Gomez P, Zunzunegui MV. Economic crisis, poverty and childhood. What are the expected short- and long-term effects for the "children of the crisis"? SESPAS report 2014. Gac Sanit. 2014;28:132-6.

33. Currie J, Almond D. Human capital development before age five. In: Ashenfelter O, Card D, editors. Handbook of labor economics. UK: Elsevier; 2011. p. 1315-486.

\section{Submit your next manuscript to BioMed Central and we will help you at every step:}

- We accept pre-submission inquiries

- Our selector tool helps you to find the most relevant journal

- We provide round the clock customer support

- Convenient online submission

- Thorough peer review

- Inclusion in PubMed and all major indexing services

- Maximum visibility for your research

Submit your manuscript at www.biomedcentral.com/submit
Biomed Central 